\title{
Mechanical properties of water alter temporal parameters of human walking
}

\author{
Yoichiro Sato ${ }^{1 *}$, Kenichi Murakami ${ }^{2}$ and Hiroyuki Fujisawa ${ }^{2}$
}

*Correspondence: sato-y@hus.ac.jp

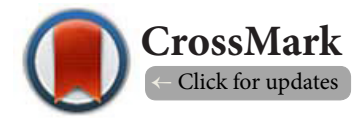

'Department of Physical Therapy, Faculty of Health Sciences, Hokkaido University of Science, Sapporo, Japan.

2Department of Rehabilitation, Faculty of Medical Science and Welfare, Tohoku Bunka Gakuen University, Sendai, Japan.

\begin{abstract}
Background: Walking in water is an effective rehabilitation exercise for patients with various diseases. However, how the mechanical properties of water alter the temporal parameters of human walking is still unclear. Therefore, the objective of the present study was to examine the durations of various gait phases relative to gait cycle at the same speeds both on land and in water.

Methods: Ten healthy male subjects walked on land and in water at slow $(2.4 \mathrm{~km} / \mathrm{h})$ and moderate $(3.6$ $\mathrm{km} / \mathrm{h}$ ) speeds. Subjects' movements were recorded using a digital videocamera. Durations of stance, singlestance, and double-stance phases relative to gait cycle were calculated.

$\underline{\text { Results: }}$ Relative stance phase duration was significantly shorter in water than on land, whereasrelative single-stance phase duration was significantly longer in water than on land. It was revealed that the buoyance effect of water alters the longer duration of single-stance phase in water compared with on land.

Conclusion: The present findings clarify that water can alter the temporal parameters of gait during walking.
\end{abstract}

Keywords: Mechanical property of water, temporal parameters, healthy adults, human walking

\section{Introduction}

Motion patterns of walking can be altered due to aging and various diseases [1-3]. Temporal parameters of motion patterns also change with changes in gaitability $[4,5]$. Most abnormal gait patterns show elongation of double-stance phase and shortening of single-stance phase [6]. Shortening of single-stance phase on the side affected by disease (e.g., hip osteoarthritis) can increase the vertical component of the ground reaction force on the contralateralside [7]. Consequently, shortening of single-stance phase on the affected side would cause secondary impairments of joints (e.g., knee osteoarthritis) and/or muscles on the unaffected side. Furthermore, as asymmetrical walking can increase metabolic and mechanical cost [8], activities of daily living can be affected due to fatigue. Individuals with a symmetrical walking over along-term duration often learn a symmetrical walking patterns. We have experienced that even if therapy can remove the cause of asymmetrical walking (e.g., pain), some patients still continue to walk asymmetrically. Thus, it is necessary for physical therapy to normalize abnormal walking pattern in parallel to removing its cause.

For alleviation of pain and prevention of consequent abnormal gait pattern, walking in water may be effective $[9, \mathbf{1 0}]$. Buoyancy-one of the mechanical properties of water-can decrease loading on the lower limb joints [11], allowing individuals to walk without pain. Consequently, walking in water might improve the temporal parameters of abnormal gait. Therefore, it is necessary to clarify how the temporal parameters of gait differ between walking on land and in water. In a previous study, Barela et al., [12] reported that duration of stance phase relative to gait cycle was approximately $60 \%$ both on land and in water. However, it was noted that subjects in their study walked at their preferred speeds, resulting in slower speeds in water than on land. This change in speed leads us to a question how much walking in water represented that on land.

Therefore, the present study addressed this issue by examining the durations of various gait phases relative to gait cycle in subjects who walked at the same speeds both on land and in water. 
Sato et al. Physical Therapy and Rehabilitation 2017,

http://www.hoajonline.com/journals/pdf/2055-2386-4-10.pdf

\section{Methods}

\section{Subjects}

Ten healthy male subjects volunteered to participate in the present study. Ages ranged from 21 to 23 years, and average height and body mass were $1.70 \pm 0.06 \mathrm{~m}$ and $63.3 \pm 6.9 \mathrm{~kg}$, respectively. The inclusion criterion was no orthopedic or neurologic disorder that could interfere with the subject's study performance. The exclusion criterion was morbidity of orthopedic or neurologic disorder in the last 6 months. We judged whether the subjects had such disorders by detailed history taking. All subjects provided informed consent after being informed of the purpose and procedure of the study. The experimental protocol was approved by the Medical Ethics Committee of Tohoku Bunka Gakuen University.

\section{Procedures}

Each subject completed all walking trials within a single day. Subjects walked on a treadmill on land (Autorunner, MT-11; Minato, Osaka, Japan), and on an underwater treadmill (Dynamizer, R3000; Tiger, Japan), which was immersed at such a depth for the water level to reach the xiphoid process of each subject $[12,13]$. Water temperature was maintained at $30^{\circ} \mathrm{C}$ to $31^{\circ} \mathrm{C}[14,15]$. Before commencing the tests, all subjects practiced walking on land and in water at the test speeds for 1 minute. Both land and water walking trials were performed at speeds of $2.4 \mathrm{~km} / \mathrm{h}$ (slow) and $3.6 \mathrm{~km} / \mathrm{h}$ (moderate) [15]. The upper extremities of each subject were crossed and held in front of the chest. Each subject walked for 3 min under each of the 4 conditions, with a 1 -min rest between consecutive trials. Subjects wore swimsuits throughout the trials, even when walking on land. Subjects' movements when walking were recorded during the last 30 seconds (ie, 20 to 25 gait cycles) of each condition in order to obtain data for steadystate walking. Twenty gait cycles were used for the analysis.

\section{Instruments and measurements}

Subjects' movements in the left sagittal plane were recorded using a stationary digital video camera (GZ-MG330-R; Victor, Kanagawa, Japan), operating at 60 frames/s. Kinematic parameters were analyzed using motion analysis software (Frame Dias V; DKH, Tokyo, Japan) [16]. Times of heel contact and toe off for both feet were defined as the temporal parameters. Duration between 2 successive left heel contacts was defined as a gait cycle. Stride frequency was calculated as number of strides per minute.

Durations of stance, single-stance, and double-stance phases were determined and calculated as percentages relative to gait cycle. Step length on the left side also was measured. The experimental setting is illustrated in Figure 1.

\section{Statistical analysis}

Two-way repeated-measures analysis of variance was used to examine the differences in kinematic data based on experimental environment and walking speed. Post hoc power

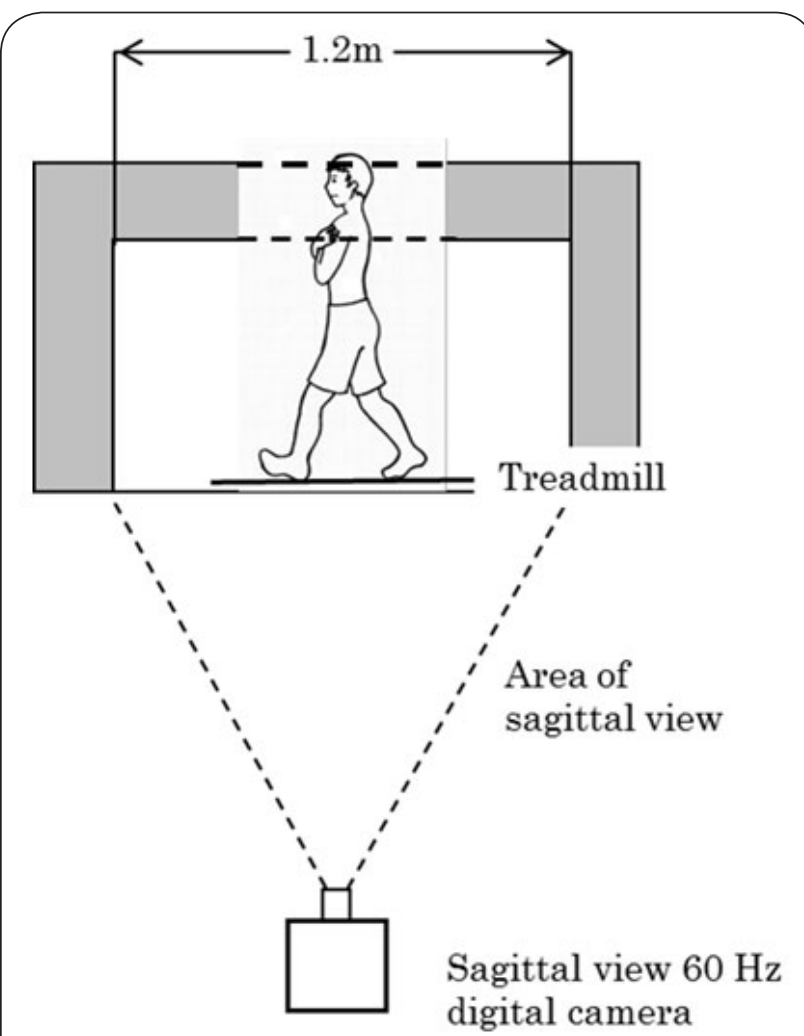

Figure 1. Experimental setup of walking trials in water.

analysis of ANOVA was performed. Furthermore, the effect size, $\eta^{2}$, of each factor (land/water or speed) of ANOVA was calculated. The minimal detectable change for the dependent variables was calculated [17]. All statistical analysis was performed using SPSS version 20.0 (IBM Corporation, Armonk, NY, USA), with significance set at $P<0.05$.

\section{Results}

When durations of stance, single-stance, and double-stance phases were compared relative to gait cycle,relative stance phase durations in water and on landunder the slow speed condition were, on average, $63.8 \%$ and $57.0 \%$, respectively, while those under the moderate speed condition were $61.8 \%$ and $54.9 \%$, respectively (Figure 2). The main effect of water and land conditions was statistically significant $(F(1,9)=758.4$, $P<0.001)$. The detection force and effect size were 1.00 and 0.989 , respectively. Moreover, relative single-stance phase duration was significantly longerin water than on land $(F$ $(1,9)=97.8, P<0.001)$, whereas relative double-stance phase duration was significantly shorter in water than on land $(F$ $(1,9)=300.4, P<0.001)$.

Step length was significantly longer in water than on land $(F(1,9)=19.4, P<0.01)$. The detection force and effect size were 0.969 and 0.674 , respectively. Stride frequency was significantly lower in water than on land $(F(1,9)=1541.8, P$ $<0.001)$, as shown in Table 1. The minimal detectable changes 
Sato et al. Physical Therapy and Rehabilitation 2017,

http://www.hoajonline.com/journals/pdf/2055-2386-4-10.pdf

Table 1. Step length and stride frequency when walking on land and in water $(n=10)$.

\begin{tabular}{|c|c|c|c|c|c|c|c|c|c|c|}
\hline \multirow[b]{3}{*}{ Variable } & \multicolumn{4}{|c|}{ Slow $(2.4$ km/h $)$} & \multicolumn{4}{|c|}{ Moderate $(3.6$ km/h) } & \multirow[t]{3}{*}{ Significance } & \multirow{3}{*}{$\begin{array}{l}\text { Effect size } \\
\text { (land-water) }\end{array}$} \\
\hline & \multicolumn{2}{|c|}{ Land } & \multicolumn{2}{|c|}{ Water } & \multicolumn{2}{|c|}{ Land } & \multicolumn{2}{|c|}{ Water } & & \\
\hline & Mean (SD) & $95 \% \mathrm{CI}$ & Mean (SD) & $95 \% \mathrm{CI}$ & Mean (SD) & $95 \%$ CI & Mean (SD) & $95 \%$ CI & & \\
\hline Step length, m & $0.49(0.05)$ & $0.45-0.53$ & $0.57(0.05)$ & $0.53-0.61$ & $0.56(0.04)$ & $0.53-0.59$ & $0.64(0.06)$ & $0.60-0.68$ & $\mathrm{P}<0.01^{* \dagger}$ & 0.674 \\
\hline $\begin{array}{l}\text { Stride frequency, } \\
\text { stride/min }\end{array}$ & $41.7(4.2)$ & $38.7-44.7$ & $35.6(2.6)$ & $33.7-37.5$ & $53.0(3.0)$ & $50.9-55.1$ & $41.6(4.4)$ & $38.5-44.7$ & $\mathrm{P}<0.01^{* \dagger}$ & 0.994 \\
\hline
\end{tabular}

CI: Confidence Intervals

${ }^{*}$ Difference between land and water

$\dagger$ Difference between walking speeds

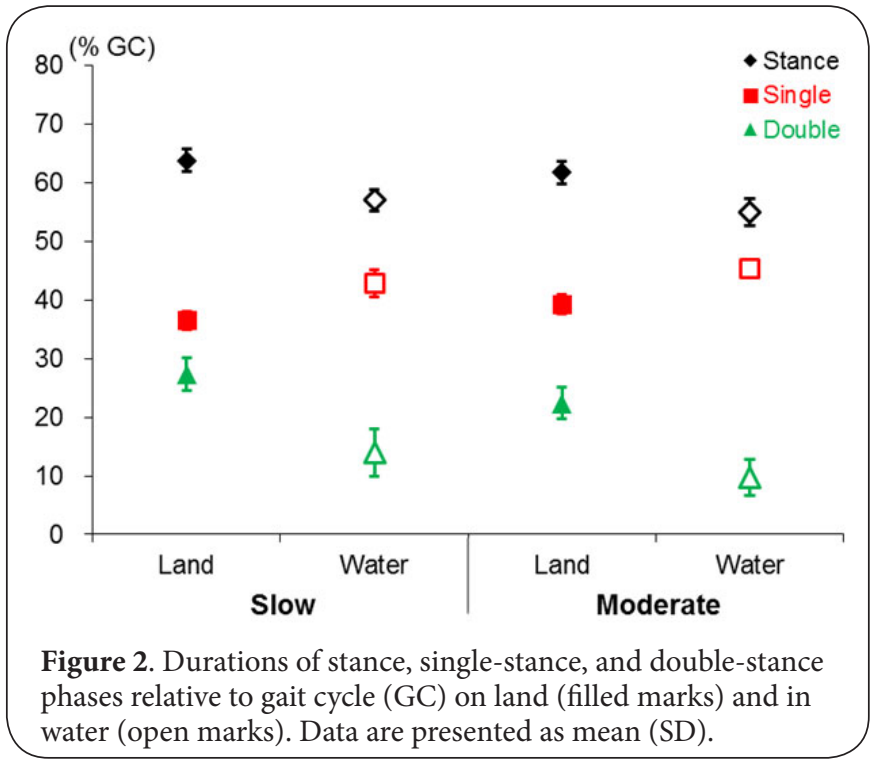

for the step length and stride frequency were 0.14 and 11.6, respectively.

\section{Discussion}

The present study examined the temporal parameters of walking on land and in water at the same speeds, and found shorter stance phase but longer single-stance phase in water than on land.

The present study revealed for the first time that relative single-stance phase duration was longer in water than on land. During normal walking on land, the center of mass reaches its highest level at approximately the middle of singlestance phase, and then falls to its lowest level at around the beginning of double-stance phase $[18,19]$. The muscles of the lower limb in the loading response phase are less active in water than on land $[12,15]$. This result would be attributed to an attenuated impact force due to buoyancy. Therefore, it is considered that the falling speed of the center of mass in the latter half of the single-stance phase would be slower in water than on land. This is likely the cause of the longer singlestance phase duration in water compared with on land. Finch et al., [20] reported that relative single-stance phase duration was lengthened with increasing suspension strength using a harness for suspension of the body. This previous finding supports the present finding because both suspension and buoyancy are forces that lift thebody.

The shorter relative stance phase duration in water compared with on land is inconsistent with a previous finding [12]. The previous study showed that stance phase duration relative to gait cycle was approximately $60 \%$ both in water and on land, without a significant difference. This inconsistency may be attributable to subjects' walking speeds. In the present study, subjects walked in water at the same speed as on land, whereas subjects in the previous study walked at their preferred speeds. Limb movements in water receive the resistance of water. As water resistance depends on movement speed of the limb [10,12], speed of the swing leg is slower in water. Therefore, longer relative swing phase duration would result in shorter relative stance phase duration.

Stride frequency is synonymous with number of gait cycles in a given time. Duration of gait cycle is determined by acceleration of gravity $(g)$ and length of the leg $(I)(\sqrt{ } \mathrm{g} / \mathrm{l})[\mathbf{2 1}, \mathbf{2 2}]$. As shown by elongation of single-stance phaseduration in water (Figure 2), buoyancy increases resistance of the fall of the body. Therefore, since walking in water is associated with longer gait cycle duration than that on land, stride frequency in water would be lower than that on land.

Step length was longer in water than on land. Althoughstep length decreases with decreasing stride frequency in order to maintain walk ratio on land $[23,24]$, the relationship between step length and stride frequency tends to differ with different environments.

In clinical situations, alternations of spatiotemporal parameters were observed $[\mathbf{2 5 , 2 6 ]}$. The present study suggests that walking in water may be effective for normalization of temporal parameters during walking for patients with unilateral disease. It is necessary to examine whether walking in water can improve abnormal gait patterns in future studies.

A limitation of this study is its small sample size. However, since both detection force and effect size showed high values, we consider that the present findings are valid. Another limitation is that the participants in the present study were healthy young males. Because of this limitation, the results of this study cannot be generalized to subjects of other ages, 
Sato et al. Physical Therapy and Rehabilitation 2017,

sexes, and to those with pathology. Such subjects should be included in future studies.

\section{Conclusions}

The present findings clarify that water can alter the temporal parameters of gait during walking.

\section{Competing interests}

The authors declare that they have no competing interests.

Authors' contributions

\begin{tabular}{|l|c|c|c|}
\hline Authors' contributions & YS & KM & HF \\
\hline Research concept and design & $\checkmark$ & -- & $\checkmark$ \\
\hline Collection and/or assembly of data & $\checkmark$ & $\checkmark$ & -- \\
\hline Data analysis and interpretation & $\checkmark$ & $\checkmark$ & -- \\
\hline Writing the article & $\checkmark$ & -- & -- \\
\hline Critical revision of the article & $\checkmark$ & $\checkmark$ & $\checkmark$ \\
\hline Final approval of article & $\checkmark$ & $\checkmark$ & $\checkmark$ \\
\hline Statistical analysis & $\checkmark$ & -- & -- \\
\hline
\end{tabular}

Acknowledgment

The authors thank Editage Ltd. for English language editing.

Publication history

Editor: Gordon John Alderink, Grand Valley State University, USA. Received: 16-May-2017 Final Revised: 26-Aug-2017

Accepted: 19-Sep-2017 Published: 26-Sep-2017

\section{References}

1. Lemke MR, Wendorff T, Mieth B, Buhl K and Linnemann M Spatiotemporal gait patterns during over ground locomotion in major depression compared with healthy controls. J Psychiatr Res. 2000; 34:277-83. | Article | PubMed

2. Martin CL, Phillips BA, Kilpatrick TJ, Butzkueven H, Tubridy N, McDonald $E$ and Galea MP. Gait and balance impairment in early multiple sclerosis in the absence of clinical disability. Mult Scler. 2006; 12:620-8. | Article I PubMed

3. Hollman JH, McDade EM and Petersen RC. Normative spatiotemporal gait parameters in older adults. Gait Posture. 2011; 34:111-8. | Article | PubMed Abstract | PubMed FullText

4. James PJ, Nicol AC and Hamblen DL. A comparison of gait symmetry and hip movements in the assessment of patients with monarticular hip arthritis. Clin Biomech (Bristol, Avon). 1994; 9:162-6. | Article | PubMed

5. Chen G, Patten C, Kothari DH and Zajac FE. Gait differences between individuals with post-stroke hemiparesis and non-disabled controls at matched speeds. Gait Posture. 2005; 22:51-6. | Article | PubMed

6. Sosnoff JJ, Sandroff BM and Motl RW. Quantifying gait abnormalities in persons with multiple sclerosis with minimal disability. Gait Posture. 2012; 36:154-6. | Article | PubMed

7. McCrory JL, White SC and Lifeso RM. Vertical ground reaction forces: objective measures of gait following hip arthroplasty. Gait Posture. 2001; 14:104-9. | Article | PubMed

8. Ellis RG, Howard KC and Kram R. The metabolic and mechanical costs of step time asymmetry in walking. Proc Biol Sci. 2013; 280:20122784. | Article | PubMed Abstract | PubMed FullText

9. Silva LE, Valim V, Pessanha AP, Oliveira LM, Myamoto S, Jones A and Natour J. Hydrotherapy versus conventional land-based exercise for the management of patients with osteoarthritis of the knee: a randomized clinical trial. Phys Ther. 2008; 88:12-21. | Article | PubMed

10. Cameron HM. Physical agents in rehabilitation. from research to practice. 4th ed. 2015; 343-380.
11. Harrison RA, Hillman M and Bulstrode S. Loading of the lower limb when walking partially immersed. Physiotherapy. 1992; 78:164-166. | Article

12. Barela AM, Stolf SF and Duarte M. Biomechanical characteristics of adults walking in shallow water and on land. J Electromyogr Kinesiol. 2006; 16:250-6. I Article | PubMed

13. Hall J, Macdonald IA, Maddison PJ and O'Hare JP. Cardiorespiratory responses to underwater treadmill walking in healthy females. Eur J Appl Physiol Occup Physiol. 1998; 77:278-84. | Article | PubMed

14. Evans BW, Cureton KJ and Purvis JW. Metabolic and circulatory responses to walking and jogging in water. Res Q. 1978; 49:442-9. PubMed

15. Masumoto K, Shono T, Hotta N and Fujishima K. Muscle activation, cardiorespiratory response, and rating of perceived exertion in older subjects while walking in water and on dry land. J Electromyogr Kinesiol. 2008; 18:581-90. | Article | PubMed

16. Kurokawa S, Fukunaga T and Fukashiro S. Behavior of fascicles and tendinous structures of human gastrocnemius during vertical jumping. $J$ Appl Physiol (1985). 2001; 90:1349-58. | Article I PubMed

17. Haley SM and Fragala-Pinkham MA. Interpreting change scores of tests and measures used in physical therapy. Phys Ther. 2006; 86:735-43. PubMed

18. Perry J. Gait analysis. normal and pathological function. 1992; 4-97. | Article

19. Rose J and Gamble JG. Human walking. 3rd ed. 2006; 1-17.

20. Finch L, Barbeau $\mathrm{H}$ and Arsenault B. Influence of body weight support on normal human gait: development of a gait retraining strategy. Phys Ther. 1991; 71:842-55. I PubMed

21. Alexander RM. Walking and running. Am. Sci. 1984; 72:348-354.

22. Rosembaum DA. Human motor control. 2nd ed. 2010; 150-187.

23. Sekiya $\mathrm{N}$, Nagasaki $\mathrm{H}$, Ito $\mathrm{H}$ and Furuna T. Optimal walking in terms of variability in step length. J Orthop Sports Phys Ther. 1997; 26:266-72. | Article | PubMed

24. Sekiya $\mathrm{N}$ and Nagasaki $\mathrm{H}$. Reproducibility of the walking patterns of normal young adults: test-retest reliability of the walk ratio(steplength/step-rate). Gait Posture. 1998; 7:225-227. | Article | PubMed

25. Sosnoff JJ, Sandroff BM and Motl RW. Quantifying gait abnormalities in persons with multiple sclerosis with minimal disability. Gait Posture. 2012; 36:154-6. | Article | PubMed

26. McCrory JL, White SC and Lifeso RM. Vertical ground reaction forces: objective measures of gait following hip arthroplasty. Gait Posture. 2001; 14:104-9. | Article | PubMed

\section{Citation:}

Sato Y, Murakami K and Fujisawa H. Mechanical properties of water alter temporal parameters of human walking. Phys Ther Rehabil. 2017; 4:10. http://dx.doi.org/10.7243/2055-2386-4-10 